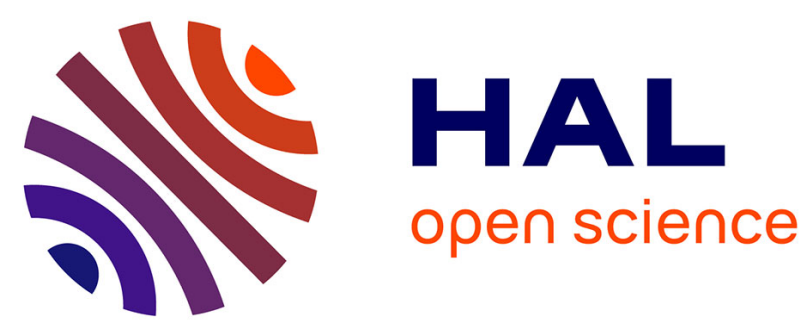

\title{
Time course of asymptomatic interstitial pulmonary oedema at high altitude.
}

Pierre Bouzat, Guillaume Walther, Thomas Rupp, Gregory Doucende, Jean-François Payen, Patrick Levy, Samuel Verges

\section{To cite this version:}

Pierre Bouzat, Guillaume Walther, Thomas Rupp, Gregory Doucende, Jean-François Payen, et al.. Time course of asymptomatic interstitial pulmonary oedema at high altitude.. Respiratory Physiology \& Neurobiology, 2012, 186 (1), pp.16-21. 10.1016/j.resp.2012.12.009 . hal-00800441

\section{HAL Id: hal-00800441 \\ https://hal.science/hal-00800441}

Submitted on 13 Mar 2013

HAL is a multi-disciplinary open access archive for the deposit and dissemination of scientific research documents, whether they are published or not. The documents may come from teaching and research institutions in France or abroad, or from public or private research centers.
L'archive ouverte pluridisciplinaire HAL, est destinée au dépôt et à la diffusion de documents scientifiques de niveau recherche, publiés ou non, émanant des établissements d'enseignement et de recherche français ou étrangers, des laboratoires publics ou privés. 


\section{Time course of asymptomatic interstitial pulmonary oedema at high altitude}

Pierre Bouzat ${ }^{\mathrm{c}, \mathrm{d}}$, Guillaume Walther ${ }^{\mathrm{e}}$, Thomas Rupp ${ }^{\mathrm{a}, \mathrm{b}}$, Gregory Doucende ${ }^{\mathrm{f}}$, Jean-François Payen $^{\mathrm{c}, \mathrm{d}}$, Patrick Levy ${ }^{\mathrm{a}, \mathrm{b}}$, Samuel Verges ${ }^{\mathrm{a}, \mathrm{b}}$

${ }^{a}$ U1042, INSERM, Batiment Jean Roget, Faculté de Médecine, 38042 Grenoble, France.

${ }^{\mathrm{b}}$ Laboratoire HP2, Université Joseph Fourier, Batiment Jean Roget, Faculté de Médecine, 38042 Grenoble, France.

${ }^{\mathrm{c}}$ Pôle Anesthésie Réanimation, CHU de Grenoble, 38042 Grenoble, France.

${ }^{\mathrm{d}}$ Grenoble Institute of Neurosciences, INSERM U836, BP 217, 38043 Grenoble, France.

${ }^{\text {e }}$ Laboratoire de Pharm-Ecologie Cardiovasculaire (EA4278), Université d'Avignon, 74 rue Louis Pasteur, 84029 Avignon, France.

${ }^{\mathrm{f}}$ Laboratoire Performance et Santé en Altitude, Université de Perpignan, UFRSTAPS, 66120 Font-Romeu, France.

\section{Correspondingauthor :}

Dr VERGES Samuel, Laboratoire HP2 (INSERM U 1042), UF Recherche sur l'Exercice, Hôpital Sud, Avenue Kimberley, 38434 Echirolles, France.

Tel: +33 4767668 60; Fax: +33 4767689 21; Email: sverges@ chu-grenoble.fr 


\section{ABSTRACT}

The time course of asymptomatic pulmonary oedema during high-altitude exposure and its potential relationship with changes in cardiac function remain to clarify.

Eleven volunteers were rapidly exposed to 4,350m during a 4-day period. Each subject received clinical examination and thoracic ultrasonography to assess ultrasound lung comets (USLC) on day 1, 2 and 3 after arrival. Echocardiography was performed on day 2 and 4 at $4,350 \mathrm{~m}$.

All subjects had a significant increase in the number of USLC on day $1(n=8 \pm 3)$, day 2 $(\mathrm{n}=7 \pm 4)$ and day $3(\mathrm{n}=3 \pm 2)$ compared to sea level $(\mathrm{n}=1 \pm 1)(P<0.01)$. Although left ventricle diastolic function and systolic tricuspid regurgitation gradient were significantly different at altitude compared to sea level, they did not correlate with the number of USLC $(P>0.05)$.

Asymptomatic pulmonary oedema seems to be transiently present in fast-ascending recreational climbers. The lack of correlation between the number of USLC and indices of cardiac changes suggest that non-cardiogenic mechanisms may underlie this transient increase in lung water.

Key words: cardiac dysfunction, hypoxia, pulmonary interstitial oedema, thoracic ultrasonography.

\section{Highlights}

- Interstitial pulmonary oedema was assessed at 4,350 $\mathrm{m}$ by ultrasonography.

- Interstitial pulmonary oedema was clearly observed the first 2 days at altitude.

- Transient interstitial pulmonary oedema is part of acclimatization to high altitude. 
- It does not relate to changes in left ventricle function or pulmonary hypertension. 


\section{INTRODUCTION}

High-Altitude Pulmonary Oedema (HAPE) is the leading cause of death from highaltitude illness in recreational climbers (Hackett et al. 2001). Few high-altitude climbers only have clinical symptoms requiring medical attention whereas asymptomatic extravascular lung water accumulation is probably more common (Cremona et al. 2002; Cogo et al. 2011; Swenson 2011). Initially devoted to diagnose alveolar-interstitial syndrome (Lichtenstein et al. 1997) in pathological situations such as acute respiratory distress syndrome or cardiogenic acute pulmonary oedema (Gargani et al. 2008), thoracic ultrasonography has been used to show extravascular lung water accumulation at high altitude (Fagenholz et al. 2007; Otto et al. 2009). The main criterion in favour of pulmonary alveolar-interstitial oedema was the presence of ultrasound lung comet (USLC) (Picano et al. 2006) which is particularly robust for assessing changes in alveolar-interstitial fluid (Jambrik et al. 2004; Agricola et al. 2005).

Pulmonary extravascular fluid accumulation in HAPE depends on the quantity of liquid escaping from the pulmonary vasculature and on the ability of the alveolar respiratory epithelium to reabsorb flood overload (Scherrer et al. 2010). The participation of these two phenomena to asymptomatic extravascular lung water accumulation remains unclear. It is well established that hypobaric hypoxia increases pulmonary capillary hydrostatic pressure (Maggiorini et al. 2001). In some subjects, the hypoxia-induced increase in capillary pressure is exaggerated, resulting in capillary stress failure and alveolar fluid flooding. However, in 26 unacclimatized subjects ascending to Monte Rosa $(4,559 \mathrm{~m})$, changes in pulmonary function assessed by spirometry, single-breath nitrogen wash-out and diffusion capacity were consistent with extravascular fluid accumulation (Senn et al. 2006) but did not relate to changes in arterial pulmonary pressure. In 18 healthy recreational climbers participating to a 
3-week trekking in Nepal, the numbers of USLC at rest progressively increased with altitude ascent, even in 14 asymptomatic subjects, with no correlation with pulmonary artery systolic pressure increase (Pratali et al. 2010). In this study, no significant changes in indices of left diastolic or systolic function were observed in high-altitude echocardiography, probably due to medication and progressive ascent. However, changes in left ventricle diastolic function have been described in 41 patients ascending to $4,559 \mathrm{~m}$ within a period of 24 hours (Allemann et al. 2004). In pathological condition like heart failure with preserve ejection fraction, diastolic dysfunction could lead to pulmonary congestion (Desai 2007). Therefore, to

clarify the participation of cardiac changes to asymptomatic alveolar-interstitial fluid accumulation in non-acclimatized climbers at rest, the time course of asymptomatic pulmonary oedema in non-acclimatized healthy subjects staying at a constant high altitude without exercise-induced fatigue and its relationship with high altitude cardiac changes remain to be investigated.

In the present study our aim was to assess (i) USLC time course in recreational climbers during a 4-day stay at 4,350 $\mathrm{m}$, avoiding the potential confounding effects of physical activity(Swenson 2011) and/or preliminary acclimatization as during trekking and (ii) the relationship between the number of USLC and echocardiographic indices of left and right cardiac functions. We hypothesized that USLC would peak on day 1 or 2 after arrival at high altitude, and would correlate with changes in cardiac function.

\section{MATERIALS AND METHODS}

Eleven male subjects (mean age $28 \pm 8$ yrs) were examined at the Grenoble University Hospital (altitude: $212 \mathrm{~m}$ ) to rule out respiratory or cardiac diseases and to establish sea level 
measurements. Subjects were usual recreational climbers with no history of HAPE during previous high-altitude ascents and were unacclimatized to high altitude (no sojourn above 1,500 $\mathrm{m}$ of altitude over the past 3 months). All subjects underwent helicopter transport at midday $( \pm 2 \mathrm{~h}$ ) to be dropped $10 \mathrm{~min}$ later at 4,350 m (Observatoire Vallot, Mont Blanc, Chamonix, France). They stayed for the next 4 days in the Observatoire Vallot without further ascent or climbing. They received no treatment to prevent or treat acute mountain sickness (AMS). The Regional Institutional Ethics Committee (Grenoble Sud-Est V) approved the design of the study and all subjects provided written informed consent.

\subsection{Clinical examination}

Clinical examination included measurements of heart rate and non-invasive blood pressure (Dinamap, GE Medical Systems Inc., Milwaukee, WI) every morning at rest in supine position. Arterial oxygen saturation $\left(\mathrm{SpO}_{2}\right)$ was measured using finger-pulse oximetry (Biox 3740 Pulse Oximeter, Ohmeda, Louisville, CO) after 30-s signal stabilization and finger warming with a warm glove during two minutes (room air temperature: $23 \pm 2^{\circ} \mathrm{C}$ at sea level and $21 \pm 2{ }^{\circ} \mathrm{C}$ at altitude). Subjects were also asked to complete self-reported questionnaires for AMS evaluation according to the Lake Louise Score (LLS, 5 items) (Roach et al. 1993) and the respiratory subscore of the Environmental Symptom Questionnaire (ESQ-

III AMS-R, 12 items) (Sampson et al. 1983). The presence of AMS was defined as LLS>3 and AMS-R $\geq 0.6$. Clinical examination took place on the morning at sea level and each morning on days 1 (D1, i.e. 20 hours after arrival at high altitude), 2 (D2) and 3 (D3).

\subsection{Thoracic ultrasonography}

Thoracic ultrasonography was performed after clinical examination, using CX-50 (Phillips, Eindhoven, Netherlands) and an abdominal 5-2 MHz probe (curvature 40R, field-of- 
view $75^{\circ}$ ) by one trained operator (PB) (Hyacinthe et al. 2011) blinded to clinical and echocardiographic results. The upper, medium and lower parts of the anterior and lateral regions of the two chest walls were sequentially examined with the subject in the supine position. USLC was defined as an echogenic, coherent, wedge-shaped signal with a narrow origin from the hyperechoic pleural line (Picano et al. 2006) (Figure 1). The comet-tail image described here extends to the edge of the screen (whereas short comet-tail artefacts may exist in other regions) and arises only from the pleural line. This ultrasound sign correlates with alveolar-interstitial oedema assessed by chest radiography, wedge pressure and extravascular lung water measured by thermodilution (Agricola et al. 2005). The number of USLC was recorded through the sequential examination of 28 intercostal lung fields located at the parasternal, midclavicular, anterior axillary, and midaxillary lines from the second to the fourth intercostal space on the left side and from the second to the fifth intercostal space on the right side. A number of USLC $\leq 5$ is a normal echographic chest pattern since healthy subjects may present a small number of USLC, especially confined laterally to the last intercostal spaces above the diaphragm(Picano et al. 2006).

\subsection{Echocardiography}

Echocardiographic studies were performed using a portable echocardiograph (Vivid Q, GE Healthcare, Horten, Norway) with a $3.5 \mathrm{MHz}$ sector scanning electronic transducer. Bidimensional, Doppler and Doppler tissue imaging measurements were performed by fully trained operator $(\mathrm{GW})$ according to standard procedures recommended by the American Society of Echocardiography (ASE) (Quinones et al. 2002; Lang et al. 2005), and based on the average of 3 cardiac cycles at sea level, on D2 and day 4 (D4) at 4,365 m, as previously described (Nagueh et al. 2009; Nottin et al. 2009). Images were acquired in cine loops triggered to the QRS complex and saved digitally for subsequent blinded off-line analysis 
with dedicated software (EchoPac 6.0, GE Healthcare). Specific recommendations of the ASE (Swardson et al. 1997) were used to assess systolic tricuspid regurgitation gradient (TR). TR as surrogate of pulmonary artery systolic pressure was calculated with the modified Bernouilli equation as described previously (Gargani et al. 2008) : $\mathrm{TR}=4 \mathrm{xV}_{\max }^{2}$.

\subsection{Statistical analysis}

Data are expressed as mean $\pm \mathrm{SD}$. Analysis of the statistical significance of temporal changes during the study period was performed using one-way analysis of variance for repeated measurements (StatView SE program, SAS Institute, Cary, NC). When a significant main effect was found, post-hoc analysis was performed with Bonferroni test for multiple comparisons, with sea level taken as the reference time. Correlations were performed using linear regression and Pearson's coefficient. Statistical significance was declared when $P \leq 0.05$.

\section{RESULTS}

\subsection{Clinical examination}

Rapid transportation to high altitude was associated with AMS symptoms, with the largest average score obtained at D1 (Table 1). There were 7 subjects presenting AMS at D1, 6 at D2 and 6 at D3. Severe AMS with LLS $>6$ was observed in 2 of these subjects. However, no significant increase in mean AMS-R score was found during the 4-day high-altitude stay compared to sea level. No subject had clinical HAPE. High altitude exposure induced tachycardia, slight increase in systolic arterial pressure and oxygen desaturation as expected (Table 1). 


\subsection{Thoracic ultrasonography}

The number of USLC increased significantly at 4,350 m compared to sea level, with a peak at D1 and a progressive reduction until D3 (Figure 2, Table 1). At sea level all subjects had normal lung pattern with USLC $\leq 5$. Eight subjects had abnormal lung patterns (defined by a number of USLC>5) at D1, 6 at D2 and only 2 at D3. The number of USLC was significantly correlated with LLS at D1 and D2 and with $\mathrm{SpO}_{2}$ at D1 (Figure 3).

\subsection{Echocardiography}

Echocardiographic measurements are presented in Table 2. Regarding systolic function of the left ventricle (LV), LV ejection fraction was not different at high altitude compared to sea level. We found a significant decrease of LV end-systolic and end-diastolic diameter at high altitude compared to sea level. Regarding diastolic function, similar changes were found on day 2 and 4 compared to sea level. Transmitral early (E) wave velocity decreased at high altitude compared to sea level whereas transmitral atrial (A) wave increased significantly resulting in reduced E/A ratio. Diastolic function changes were also observed regarding averaged mitral annular motion velocity during early (Em) and late (Am) diastole using Doppler tissue imaging. However, all values remained in the normal range of LV diastolic function. TR increased significantly at high altitude compared to sea level. No correlation was observed between USLC and echocardiographic measurements at any time, in particular neither with TR nor with E/A ratio (Figure 4).

\section{DISCUSSION}


This is the first study to provide a follow-up evaluation of asymptomatic alveolarinterstitial pulmonary oedema using ultrasonography during a 4-day period at a constant highaltitude, without any medication or exercise-induced fatigue. In this context, we reported a peak USLC score on the first day at 4,350 $\mathrm{m}$ followed by a progressive decrease until day 3 in 11 healthy subjects. The amount of USLC correlated with LLS and $\mathrm{SpO}_{2}$ but not with changes in LV diastolic function or pulmonary arterial pressure. These results indicate that extravascular pulmonary fluid accumulation is highly prevalent in fast-ascending highaltitude recreational climbers, resolved within few days, but does not correlate with cardiac changes during the first days of acclimatization.

While clinical HAPE requiring medical attention has a low prevalence (Hackett et al. 2001), silent pulmonary oedema may frequently occur in recreational climbers. Pulmonary hypertension is a major factor contributing to the pathogenesis of pulmonary oedema (Scherrer et al. 2010). Thus, a high incidence of asymptomatic pulmonary oedema is likely since most healthy subjects develop hypoxia-induced arterial pulmonary hypertension. In 262 climbers ascending to Monte Rosa (Switzerland, 4,559 m), 146 had an increase in closing volume at altitude suggesting increased pulmonary extravascular fluid (Cremona et al. 2002). Conversely, extensive conventional pulmonary function testing, using body plethysmography and closing volume measurements, failed to demonstrate extravascular fluid accumulation in 34 healthy subjects ascending to 4,559 m (Dehnert et al. 2010), suggesting that these methods were not sensitive enough to detect pulmonary oedema even in case of early mild HAPE (four subjects).To overcome these limitations, ultrasound sign of alveolar-interstitial syndrome as used in lung pathologies (Lichtenstein et al. 1997) can be an alternative method. Thoracic ultrasonography with the sign of USLC was first used to diagnose and monitor HAPE by Fagenholz et al. (2007) in eleven consecutive patients presenting to the Himalayan Rescue 
Association clinic $(4,240 \mathrm{~m})$ with clinical HAPE. Compared to control asymptomatic subjects, patients with HAPE had significantly larger USLC scores and lower $\mathrm{SpO}_{2}$. USLC score decreased under treatment with improved oxygenation and clinical status, which indicated that thoracic ultrasonography was sensitive enough to follow variations of extravascular pulmonary fluid accumulation. Thoracic ultrasonography seems also able to characterize subclinical HAPE. Indeed, during a 3-week trekking in Nepal with progressive ascent to a maximum altitude of $5,130 \mathrm{~m}$, all 18 recreational climbers showed USLC $(17 \pm 8$ on average at 5,130 m) while only three developed clinical HAPE (Pratali et al. 2010). A linear correlation was also found between LLS, $\mathrm{SpO}_{2}$ and the number of USLC.

Our study is the first one to provide a follow-up evaluation of asymptomatic alveolarinterstitial pulmonary oedema using ultrasonography during a 4-day period at a constant highaltitude, without any medication. The study design provides an assessment of alveolarinterstitial pulmonary oedema at high-altitude independently of potential confounding factors (i.e. other than hypobaric hypoxia exposure), such as medication, preliminary acclimatization (thanks to rapid helicopter ascent from sea level) and strenuous physical activity (known to promote pulmonary oedema at altitude (West et al. 1995)), as present in previous studies including prolonged ascent periods. The peak USLC score occurred early during the sojourn at high altitude, on the first morning. Compared to previous reports of USLC at high altitude, the peak score observed in the present study is clearly lower that the average amount of USLC reported in HAPE patients (31 \pm 11 in Fagenholtz et al. (2007)). The peak score measured on day 1 was also slightly lower than those reported by Pratali et al. (2010) despite progressive subject acclimatization in this later study. Low individual AMS susceptibility (our subjects previously climbed repeatedly above 3,500 m with no HAPE history), lower altitude and the absence of prolonged physical effort (as performed during trekking in previous reports) in the present study probably account for this difference. We found a linear correlation between 
USLC, LLS and $\mathrm{SpO}_{2}$ as described by Pratali et al. (2010). The peak of USLC at D1 coincided with the maximum intensity of AMS symptoms as assessed by LLS, emphasizing that USLC and symptoms of AMS probably share some common mechanisms associated with hypobaric hypoxia. Nevertheless, the absence of specific respiratory symptoms as indicated by non significant change in AMS-R score at high altitude despite significant increase in USLC emphasizes that pulmonary oedema remained clinically silent in the present study. Hence, although clinically-silent pulmonary extravascular fluid accumulation and clinical HAPE are thought to share some common mechanisms, the reasons why alveolar-interstitial pulmonary fluid accumulation progressively resolves in some subjects as in the present study while other susceptible subjects would develop HAPE remain to be elucidated.

HAPE is initially a hydrostatic-type oedema (Maggiorini et al. 2001) with altered alveolar-capillary permeability (Swenson et al. 2002). In several pathological conditions, patients can develop hydrostatic pulmonary oedema secondary to left heart failure (Vivona et al. 2001). Since changes in LV function have been reported at altitude (Allemann et al. 2004; Otto et al. 2009), myocardial performance may contribute to the accumulation of extravascular lung water. In healthy mountaineers ascending within 24 hours to $4,559 \mathrm{~m}$ (Allemann et al. 2004; Otto et al. 2009), A wave increased at high altitude resulting in decreased E/A ratio while Doppler tissue imaging showed a reduction of $\mathrm{A}_{\mathrm{m}}$. In addition, changes in diastolic function correlated with the increase of systolic pulmonary arterial pressure, but no interstitial pulmonary oedema measurement was performed. In the present study, we observed similar LV diastolic and TR changes and we hypothesized that changes in LV function associated with the right ventricle overload would relate to interstitial pulmonary oedema. However, changes in $\mathrm{E} / \mathrm{A}$ ratio, $\mathrm{E}_{\mathrm{m}} / \mathrm{A}_{\mathrm{m}}$ ratio and $\mathrm{TR}$ did not correlate with the amount of USLC at altitude. Also, changes in LV function were similar at day 2 and day 4 while the amount of USLC decreased at day 3 with only 2 subjects having abnormal lung 
pattern at this time. Hence, the absence of correlation as well as distinct kinetics of cardiac changes and alveolar-interstitial pulmonary oedema suggest that these two mechanisms were not related. These results corroborate data from Mason et al. (Mason et al. 2003) indicating that extravascular lung water measured by electrical impedance tomography in 20 healthy subjects fast ascending to 3,800 $\mathrm{m}$ did not correlate with arterial pulmonary hypertension nor with changes in E/A ratio.

At the early stage of HAPE, alveolar pulmonary oedema could be related to an impaired ability of the alveolar epithelium to prevent alveolar flooding. Early inflammatory changes inducing increase in capillary permeability cannot be excluded either. However, an increase in inflammatory proteins and mediators in broncho-alveolar lavage fluid have been obtained in patients at a later stage of HAPE (Schoene et al. 1988). Moreover, a study using ${ }^{67}$ Ga-labeled transferrin protein transport ratio as a marker of pulmonary capillary leak in subjects exposed to high altitude (4,560 m for 72 hours) did not show any change in vascular permeability between low and high altitude (Sartori et al. 2010). In an in vivo experimental study, Vivona et al. (2001) showed that sodium (Na) transport decreases due to a reduction of epithelial $\mathrm{Na}$ channel activity and $\mathrm{Na} / \mathrm{K}$-ATPase activity. Down regulation of these two main $\mathrm{Na}$ proteins has been also described after prolonged $(>12 \mathrm{~h})$ hypoxia in cultured alveolar epithelial cells (Planes et al. 1996). Therefore, considering the main mechanisms possibly involved in extravascular pulmonary fluid accumulation and the absence of correlation between silent alveolar-interstitial pulmonary fluid accumulation and pulmonary hypertension or LV diastolic function changes, impairment of extravascular fluid clearance might explain USLC in the present study.

Our study presented several limitations. Firstly, subjects were not susceptible to clinical HAPE during standard progressive ascents and, indeed, did not develop clinical HAPE during their stay at 4,365m. Our aim was to explore specifically silent pulmonary fluid 
accumulation in healthy mountaineers, but hypothesis regarding sub-clinical interstitial pulmonary oedema may not be extended to clinical HAPE. Nevertheless, this study provides strong evidence of transient physiological pulmonary fluid accumulation at high altitude in climbers with no susceptibility to HAPE and no respiratory symptoms, which adds to our understanding of physiological adaptations to high-altitude. Secondly, due to logistical issues, thoracic ultrasonography and echocardiography measurements could not be performed everyday during the 4-day period. Nevertheless, we believe that the absence of correlation between cardiac and pulmonary variables at any time as well as different kinetics (recovery of interstitial pulmonary oedema on day 3 with similar LV changes on days 2 and 4) strongly suggest that interstitial oedema and cardiac changes were distinct mechanisms in the present study. Thirdly, the comet-tail artefact is not specific to acute altitude-induced extravascular fluid accumulation but could also be seen in chronic interstitial lung disease or pneumonia (Agricola et al. 2005). However normal chest patterns at low altitude could exclude such pathologies in our study. Finally, the number of subjects was small and the underlying mechanisms of silent pulmonary oedema at high altitude remains to be further investigated in larger populations.

In conclusion, asymptomatic alveolar-interstitial pulmonary oedema peaks within $24 \mathrm{~h}$ and then progressively resolves in recreational climbers non-predisposed to HAPE exposed to a rapid high-altitude ascent. Extravascular fluid accumulation correlates with AMS severity and $\mathrm{SpO}_{2}$. These results suggest that transient interstitial pulmonary oedema is part of subject acclimatization to high altitude. This phenomenon as characterized by chest sonography seems not to be related to changes in LV function neither with pulmonary hypertension. Further studies are needed to clarify the mechanisms underlying asymptomatic and transient extravascular fluid accumulation at high altitude. 


\section{Acknowledgements}

We thank all the subjects for participating to this study and the Rhone-Alpes Region for financial support. 


\section{REFERENCES}

Agricola, E., Bove, T., Oppizzi, M., Marino, G., Zangrillo, A., Margonato, A., Picano, E., 2005. "Ultrasound comet-tail images": a marker of pulmonary edema: a comparative study with wedge pressure and extravascular lung water. Chest 127, 1690-1695.

Allemann, Y., Rotter, M., Hutter, D., Lipp, E., Sartori, C., Scherrer, U., Seiler, C., 2004. Impact of acute hypoxic pulmonary hypertension on LV diastolic function in healthy mountaineers at high altitude. Am J Physiol Heart Circ Physiol 286, H856-862.

Cogo, A., Miserocchi, G., 2011. Pro: Most climbers do not develop subclinical interstitial pulmonary edema - Rebuttal. High Alt Med Biol 12, 129-130.

Cremona, G., Asnaghi, R., Baderna, P., Brunetto, A., Brutsaert, T., Cavallaro, C., Clark, T.M., Cogo, A., Donis, R., Lanfranchi, P., Luks, A., Novello, N., Panzetta, S., Perini, L., Putnam, M., Spagnolatti, L., Wagner, H., Wagner, P.D., 2002. Pulmonary extravascular fluid accumulation in recreational climbers: a prospective study. Lancet 359, 303-309.

Dehnert, C., Luks, A.M., Schendler, G., Menold, E., Berger, M.M., Mairbaurl, H., Faoro, V., Bailey, D.M., Castell, C., Hahn, G., Vock, P., Swenson, E.R., Bartsch, P., 2010. No evidence for interstitial lung oedema by extensive pulmonary function testing at 4,559 m. Eur Respir J 35, 812-820.

Desai, A., 2007. Current understanding of heart failure with preserved ejection fraction. Curr Opin Cardiol 22, 578-585.

Fagenholz, P.J., Gutman, J.A., Murray, A.F., Noble, V.E., Thomas, S.H., Harris, N.S., 2007. Chest ultrasonography for the diagnosis and monitoring of high-altitude pulmonary edema. Chest 131, 1013-1018. 
Gargani, L., Frassi, F., Soldati, G., Tesorio, P., Gheorghiade, M., Picano, E., 2008. Ultrasound lung comets for the differential diagnosis of acute cardiogenic dyspnoea: a comparison with natriuretic peptides. Eur J Heart Fail 10, 70-77.

Hackett, P.H., Roach, R.C., 2001. High-altitude illness. N Engl J Med 345, 107-114.

Hyacinthe, A.C., Broux, C., Francony, G., Genty, C., Bouzat, P., Jacquot, C., Albaladejo, P., Ferretti, G.R., Bosson, J.L., Payen, J.F., 2011. Diagnostic accuracy of ultrasonography in the acute assessment of common thoracic lesions after trauma. Chest 141, 1177-1183.

Jambrik, Z., Monti, S., Coppola, V., Agricola, E., Mottola, G., Miniati, M., Picano, E., 2004. Usefulness of ultrasound lung comets as a nonradiologic sign of extravascular lung water. Am J Cardiol 93, 1265-1270.

Lang, R.M., Bierig, M., Devereux, R.B., Flachskampf, F.A., Foster, E., Pellikka, P.A., Picard, M.H., Roman, M.J., Seward, J., Shanewise, J.S., Solomon, S.D., Spencer, K.T., Sutton, M.S., Stewart, W.J., 2005. Recommendations for chamber quantification: a report from the American Society of Echocardiography's Guidelines and Standards Committee and the Chamber Quantification Writing Group, developed in conjunction with the European Association of Echocardiography, a branch of the European Society of Cardiology. J Am Soc Echocardiogr 18, 1440-1463.

Lichtenstein, D., Meziere, G., Biderman, P., Gepner, A., Barre, O., 1997. The comet-tail artifact. An ultrasound sign of alveolar-interstitial syndrome. Am J Respir Crit Care Med 156, 1640-1646.

Maggiorini, M., Melot, C., Pierre, S., Pfeiffer, F., Greve, I., Sartori, C., Lepori, M., Hauser, M., Scherrer, U., Naeije, R., 2001. High-altitude pulmonary edema is initially caused by an increase in capillary pressure. Circulation 103, 2078-2083.

Mason, N.P., Petersen, M., Melot, C., Imanow, B., Matveykine, O., Gautier, M.T., Sarybaev, A., Aldashev, A., Mirrakhimov, M.M., Brown, B.H., Leathard, A.D., Naeije, R., 2003. 
Serial changes in nasal potential difference and lung electrical impedance tomography at high altitude. J Appl Physiol 94, 2043-2050.

Nagueh, S.F., Appleton, C.P., Gillebert, T.C., Marino, P.N., Oh, J.K., Smiseth, O.A., Waggoner, A.D., Flachskampf, F.A., Pellikka, P.A., Evangelista, A., 2009. Recommendations for the evaluation of left ventricular diastolic function by echocardiography. J Am Soc Echocardiogr 22, 107-133.

Nottin, S., Doucende, G., Schuster, I., Tanguy, S., Dauzat, M., Obert, P., 2009. Alteration in left ventricular strains and torsional mechanics after ultralong duration exercise in athletes. Circ Cardiovasc Imaging 2, 323-330.

Otto, C., Hamilton, D.R., Levine, B.D., Hare, C., Sargsyan, A.E., Altshuler, P., Dulchavsky, S.A., 2009. Into thin air: extreme ultrasound on Mt Everest. Wilderness Environ Med 20, 283-289.

Picano, E., Frassi, F., Agricola, E., Gligorova, S., Gargani, L., Mottola, G., 2006. Ultrasound lung comets: a clinically useful sign of extravascular lung water. J Am Soc Echocardiogr 19, 356-363.

Planes, C., Friedlander, G., Loiseau, A., Amiel, C., Clerici, C., 1996. Inhibition of Na-KATPase activity after prolonged hypoxia in an alveolar epithelial cell line. Am J Physiol 271, L70-78.

Pratali, L., Cavana, M., Sicari, R., Picano, E., 2010. Frequent subclinical high-altitude pulmonary edema detected by chest sonography as ultrasound lung comets in recreational climbers. Crit Care Med 38, 1818-1823.

Quinones, M.A., Otto, C.M., Stoddard, M., Waggoner, A., Zoghbi, W.A., 2002. Recommendations for quantification of Doppler echocardiography: a report from the Doppler Quantification Task Force of the Nomenclature and Standards Committee of the American Society of Echocardiography. J Am Soc Echocardiogr 15, 167-184. 
Roach, R.C., Bartsch, P., Hackett, P.H., Oelz, O., 1993. The lake louise acute mountain sickness scoring system. In: Sutton, J.R., Coates, J., S., H.C. (Eds.), Hypoxia and Molecular Medicine, Queen City Printers, pp. 272-274

Sampson, J.B., Cymerman, A., Burse, R.L., Maher, J.T., Rock, P.B., 1983. Procedures for the measurement of acute mountain sickness. Aviat Space Environ Med 54, 1063-1073.

Sartori, C., Rimoldi, S.F., Scherrer, U., 2010. Lung fluid movements in hypoxia. Prog Cardiovasc Dis 52, 493-499.

Scherrer, U., Rexhaj, E., Jayet, P.Y., Allemann, Y., Sartori, C., 2010. New insights in the pathogenesis of high-altitude pulmonary edema. Prog Cardiovasc Dis 52, 485-492.

Schoene, R.B., Swenson, E.R., Pizzo, C.J., Hackett, P.H., Roach, R.C., Mills, W.J., Jr., Henderson, W.R., Jr., Martin, T.R., 1988. The lung at high altitude: bronchoalveolar lavage in acute mountain sickness and pulmonary edema. J Appl Physiol 64, 2605-2613.

Senn, O., Clarenbach, C.F., Fischler, M., Thalmann, R., Brunner-La Rocca, H., Egger, P., Maggiorini, M., Bloch, K.E., 2006. Do changes in lung function predict high-altitude pulmonary edema at an early stage? Med Sci Sports Exerc 38, 1565-1570.

Swardson, C.J., Lichtenstein, D.L., Wang, S., Montelaro, R.C., Kociba, G.J., 1997. Infection of bone marrow macrophages by equine infectious anemia virus. Am J Vet Res 58, 1402-1407.

Swenson, E.R., 2011. CON: Most climbers do not develop subclinical interstitial pulmonary edema. High Alt Med Biol 12, 125-128.

Swenson, E.R., Maggiorini, M., Mongovin, S., Gibbs, J.S., Greve, I., Mairbaurl, H., Bartsch, P., 2002. Pathogenesis of high-altitude pulmonary edema: inflammation is not an etiologic factor. JAMA 287, 2228-2235. 
Vivona, M.L., Matthay, M., Chabaud, M.B., Friedlander, G., Clerici, C., 2001. Hypoxia reduces alveolar epithelial sodium and fluid transport in rats: reversal by betaadrenergic agonist treatment. Am J Respir Cell Mol Biol 25, 554-561.

West, J.B., Colice, G.L., Lee, Y.J., Namba, Y., Kurdak, S.S., Fu, Z., Ou, L.C., MathieuCostello, O., 1995. Pathogenesis of high-altitude pulmonary oedema: direct evidence of stress failure of pulmonary capillaries. Eur Respir J 8, 523-529. 


\section{FIGURE LEGENDS}

Figure 1. Ultrasound image of lung-comet tail (USLC, white arrow) in a subject at 4,350 m.

Figure 2. Individual ultrasound lung comets (USLC) time course at sea level, first (D1), second (D2) and third (D3) days at 4,350 $\mathrm{m}$.

Figure 3. Correlations between ultrasound lung comets (USLC), Lake Louise Score and arterial oxygen saturation the first (D1, panel A) and second (D2, panel B) days at 4,350 m.

Figure 4.Correlations between ultrasound lung comets (USLC), E/A ratio and systolic tricuspid regurgitation gradient on day 2 (D2) at 4,350 m. 
Table 1. Clinical and thoracic ultrasonographic data obtained at sea level and on day 1 (D1), day 2 (D2) and day 3 (D3) after the arrival at 4,350 $\mathrm{m}$.

\begin{tabular}{lcccc}
\hline & Sea level & D1 & D2 & D3 \\
\hline LLS (pts) & $1 \pm 1$ & $5 \pm 3^{*}$ & $4 \pm 3^{*}$ & $3 \pm 3^{*}$ \\
ESQ-III AMS-R (pts) & $0.16 \pm 0.15$ & $0.53 \pm 0.41$ & $0.41 \pm 0.39$ & $0.36 \pm 0.42$ \\
HR (beats/min) & $56 \pm 10$ & $69 \pm 10^{*}$ & $68 \pm 13^{*}$ & $65 \pm 10^{*}$ \\
SAP (mmHg) & $120 \pm 8$ & $126 \pm 10^{*}$ & $129 \pm 8^{*}$ & $132 \pm 8^{*}$ \\
DAP (mmHg) & $66 \pm 9$ & $65 \pm 8$ & $68 \pm 11$ & $72 \pm 9$ \\
MAP (mmHg) & $104 \pm 6$ & $107 \pm 7$ & $107 \pm 9$ & $114 \pm 8^{*}$ \\
Arterial oxygen saturation (\%) & $99 \pm 0$ & $83 \pm 4^{*}$ & $82 \pm 2^{*}$ & $84 \pm 2^{*}$ \\
USLC (n) & $1 \pm 1$ & $8 \pm 3^{*}$ & $7 \pm 4^{*}$ & $3 \pm 2^{*}$ \\
\hline
\end{tabular}

Values are mean \pm SD. LLS, Lake Louise Score; ESQ-III AMS-R, respiratory subscore of the environmental symptom questionnaire; HR, heart rate; SAP, systolic arterial blood pressure; MAP, mean arterial blood pressure; DAP, diastolic arterial blood pressure; USLC, ultrasound lung comet. ${ }^{*} P<0.05$ vs. Sea level. 
Table 2.Echocardiographic measurements at sea level, the second day (D2) and the fourth day (D4) at 4,350 m.

\begin{tabular}{|c|c|c|c|}
\hline & Sea level & D2 & D4 \\
\hline LV EF (\%) & $61 \pm 8$ & $62 \pm 6$ & $59 \pm 2$ \\
\hline $\mathrm{SV}(\mathrm{ml})$ & $77 \pm 15$ & $70 \pm 17$ & $73 \pm 15$ \\
\hline LV ESd (mm) & $33 \pm 3$ & $31 \pm 3^{*}$ & $31 \pm 3^{*}$ \\
\hline LV EDd (mm) & $53 \pm 3$ & $51 \pm 3^{*}$ & $51 \pm 2 *$ \\
\hline LV ESV (ml) & $42 \pm 12$ & $38 \pm 8$ & $43 \pm 6$ \\
\hline LV EDV (ml) & $106 \pm 23$ & $103 \pm 19$ & $105 \pm 16$ \\
\hline E wave velocity $(\mathrm{cm} / \mathrm{sec})$ & $78 \pm 13$ & $66 \pm 11^{*}$ & $69 \pm 12 *$ \\
\hline A wave velocity $(\mathrm{cm} / \mathrm{sec})$ & $43 \pm 7$ & $47 \pm 5^{*}$ & $48 \pm 6^{*}$ \\
\hline $\mathrm{E} / \mathrm{A}$ ratio & $1.9 \pm 0.4$ & $1.4 \pm 0.2 *$ & $1.5 \pm 0.3 *$ \\
\hline Transmitral IVRT (ms) & $56 \pm 18$ & $59 \pm 19$ & $55 \pm 20$ \\
\hline Averaged Em velocity $(\mathrm{cm} / \mathrm{sec})$ & $15 \pm 2$ & $16 \pm 2 *$ & $16 \pm 2$ \\
\hline Averaged Am velocity $(\mathrm{cm} / \mathrm{sec})$ & $7 \pm 1$ & $9 \pm 2 *$ & $8 \pm 2 *$ \\
\hline Averaged Em/Am ratio & $2.0 \pm 0.5$ & $1.9 \pm 0.5$ & $2.0 \pm 0.5$ \\
\hline $\begin{array}{l}\text { Systolic tricuspid regurgitation } \\
\text { gradient }(\mathrm{mmHg})\end{array}$ & $15 \pm 5$ & $29 \pm 10^{*}$ & $27 \pm 6^{*}$ \\
\hline
\end{tabular}

Values are mean \pm SD. LV, left ventricle; EF, ejection fraction; SV, stroke volume; ESd, end-systolic diameter; EDd, end-diastolic diameter; ESV, end-systolic volume; EDV, end-diastolic volume; IVRT, isovolumic relaxation time. ${ }^{*} P<0.05 v s$. Sea level. 